\title{
Use of emerging technologies in flipped classes
}

\author{
Huguet, Carme ${ }^{\text {a }}$; Pearse, Jillian ${ }^{\text {a }}$; Noè, Leslie F. ${ }^{\text {a }}$; Castillo Ruiz, Nataly ${ }^{\text {a }}$, Valencia, \\ Diego M. ' ; Jimenez Heredia, Alexa ${ }^{\text {b }}$; Patiño Avedaño, Mónica Andrea ${ }^{\text {b }}$ \\ ${ }^{\mathrm{a}}$ Geociencias, Universidad de los Andes, Colombia, ${ }^{\mathrm{b}}$ Centro de Innovación en tecnología y \\ educación, Universidad de los Andes, Colombia
}

\begin{abstract}
The need for this innovation stems from the constraints of teaching an applied science course to a large cohort of approximately 500 students which makes it impossible to include practical activities. This was compounded by the fact that the course had students with different levels of science knowledge. The aim of our pedagogic innovation was two-fold: to make the basic concepts more understandable for a broad audience of non-science major students, while maintaining a level of difficulty and rigour sufficient to challenge and provide a sound basis for students from the Geosciences undergraduate program. We used a flipped classroom strategy supported by information and communication technologies. Material was provided online before the class so students could acquire basic concepts and identify gaps in their knowledge, and in the classroom the concepts were applied in group activities. Additionally we used the online quiz tool Socrative for students to self-assess their learning. This work was supported by post-class follow-up activities. As a result we observed a substantial increase in student motivation and engagement in their learning process and greater interaction between students and between students and teachers. Furthermore there was an improvement of overall performance with fewer students failing the course.
\end{abstract}

Keywords: Flipped classroom; Sicua+ blackboard; Socrative quizzes; Learning appropriation. 


\section{Introduction}

The globalization and ready accessibility of information nowadays has forced a new educational model based on competencies where the student is expected to acquire autonomy and to appropriate the learning process. Colombia has until very recently followed a traditional education model and is now trying to move to a competency-based model that helps graduates to develop better skills for the professional environment and career development (Salas, 2010).

The Geosciences course at Los Andes University, Bogota, is the gateway to the Geosciences undergraduate degree, but it is also a basic subject taken as a science elective by a large number of students in programs as varied as engineering, social sciences and music. The challenge is to make this subject accessible to this large group of students while maintaining enough rigour to challenge and provide a sound basis for students from the Geosciences program. Geoscience, like all natural sciences, should be complemented by a practical or laboratory session, but this is not feasible for this course due to the large number of students ( 500 per semester) and the small number of professors that the department has ( 7 at the moment of innovation). The Geosciences course covers a wide range of topics to understand the Earth, including the physical, chemical, and biological principles that explain the formation, structure, dynamics and history of our planet. Previous attempts have been made to make classes more dynamic by presenting rock samples, fossils, minerals and maps during the lectures (e.g. Millis, 2014); and while this may improve motivation, it is also not practical for large groups.

The main aims of our innovation were to make the course content accessible for very heterogeneous students groups and to improve their transversal skill set. We used the theoretical framework of the Socratic method, in which we asked the students specific questions which helped them create new knowledge and appropriate the learning process through their resolution (e.g. Chin, 2007).

The innovation was applied in half of the lecture sessions, and was divided into three modules addressing the traditionally more problematic areas using information and telecommunication technologies (TICs) that have been shown to improve concept comprehension (e.g. Badia 2006; González-Coma et al. 2015). The three modules included: one on plate tectonics, volcanos and earthquakes (M1), one on atmosphere, oceans, climate and paleoclimate (M2) and one on minerals, the rock cycle and the 3 basic types of rocks (M3). Each class within the module required the students to complete a pre-class activity which provided the theoretical bases for the development of in-class group activities following the flipped class strategy. The flipped class strategy consists of students actively gathering the information outside of class by reading, watching videos, or completing other activities and then in class, doing the kind of activity typically assigned as homework: 
solving problems with their professors or peers, and applying what they learn to new contexts (e.g. Berrett 2012; Garza 2016; Wallace et al. 2014). Students were then required to do a post-class activity in order to reinforce the learning of key concepts, leading to longterm learning (e.g. Wallace, 2014).

Pre-class activities were uploaded to the University's SICUA+ virtual platform based on Blackboard Learn ${ }^{\circ}$, which is easily accessible by all students. The methodology also introduced the use of Socrative (https://socrative.com/) for online quizzes. This tool was used for two purposes: first to give the teacher feedback on student concept acquisition; and second, to help students auto-evaluate their knowledge and thus improve the learning appropriation process.

This new strategy is expected to benefit students by giving them the opportunity to apply the concepts acquired before class in a practical way and at their own pace, which we expect will promote their interest and motivation as well as their ability to learn selfsufficiency. Therefore the innovation should address the challenges of a competency-based education model (e.g. Salas 2010), which produces creative and innovative professionals. It should also allow teachers more time to provide individual attention to students, answer their questions, and thus meet the learning goals of the course despite the large size of the class.

\section{Methods}

The project was designed in 2015 and a pilot was implemented the first semester of 2016 (January to June), after which adjustments were made according to feedback from both students and professors. The results presented here correspond to the implementation phase during the second semester of 2016 (July to December).

\subsection{Tools applied to the course}

We used SICUA ${ }^{+}$Blackboard ${ }^{\bullet}$ to deliver all the necessary materials to prepare classes, formulate hypotheses or create a previous cognitive imbalance. The pre-class activities included short videos, maps, or texts along with questions that the students had to answer before the class. The virtual platform was also used to upload lectures and other materials so they were readily available to students.

Self-assessment was done with Socrative (https://socrative.com/). This is an online app by MasteryConnect which is free and accessible to students. Teachers are able to create a a free account and upload quizzes and implement them in various ways, including teacherpaced, instantaneous feedback, or races between students. After the quiz a detailed report is provided, including statistical data on student performance. 


\subsection{Evaluation of the innovation}

The usefulness of both the technological tools and the class activities in students learning and motivation was assessed in two ways. First, the whole class was asked to complete an online survey with general questions about the course as well as a specific evaluation of each class module, including the tools, materials, and types of activity implemented and their usefulness to them for their learning process. Students were requested to fill out the online survey after M1 and their answers were used to improve next two modules. The same online survey was done at the end of M3. The general online survey was completed by 107 students out of 150 that took classes using the new methodology.

Additionally a subset of 25 students were asked to attend a focus group where some of the answers were examined in more detail and students were given the freedom to suggest changes to the overall methodology and to specific activities. Focus groups were done after M1 and M2+M3 immediately after online survey completion in order to assess the different phases of the project.

\section{Results and discussion}

\subsection{Relevance of pre-class activities for the learning process}

Pre-Class activities loaded into the online platform were perceived by the students to be key for their learning process (Fig. 1). In M1 (module on plate tectonics), pre-class activities were rated to be very relevant to their learning process by $85.9 \%$ of the students; and as the course progressed and students grew more used to the methodology, that percentage went up to $91 \%$ in M2 and M3 (Fig. 1). Very few students disagreed on the usefulness of the pre-class activities and during the focus group discussions, those students who did disagree were mainly identified to be those not attending classes regularly and thus not able to apply the concepts in the activities during class.

Our results are in agreement with previous studies presenting flipped class strategies as a better way of learning (e.g. Berrett 2012; Garza 2016; Wallace et al. 2014). Clearly the students benefit from the application of previously acquired concepts to activities where those concepts are put into a practical frame.

We noticed a great improvement in student preparation of classes compared to groups not using the flipped class strategy. The fact that they knew the basic concepts before coming to the class improved their motivation to do the activities (based on focus group results) and therefore their understanding of key concepts. But additionally it improved their learning process, as shown by a significant improvement in their test results compared to sections not using the new methodology (results not shown). 


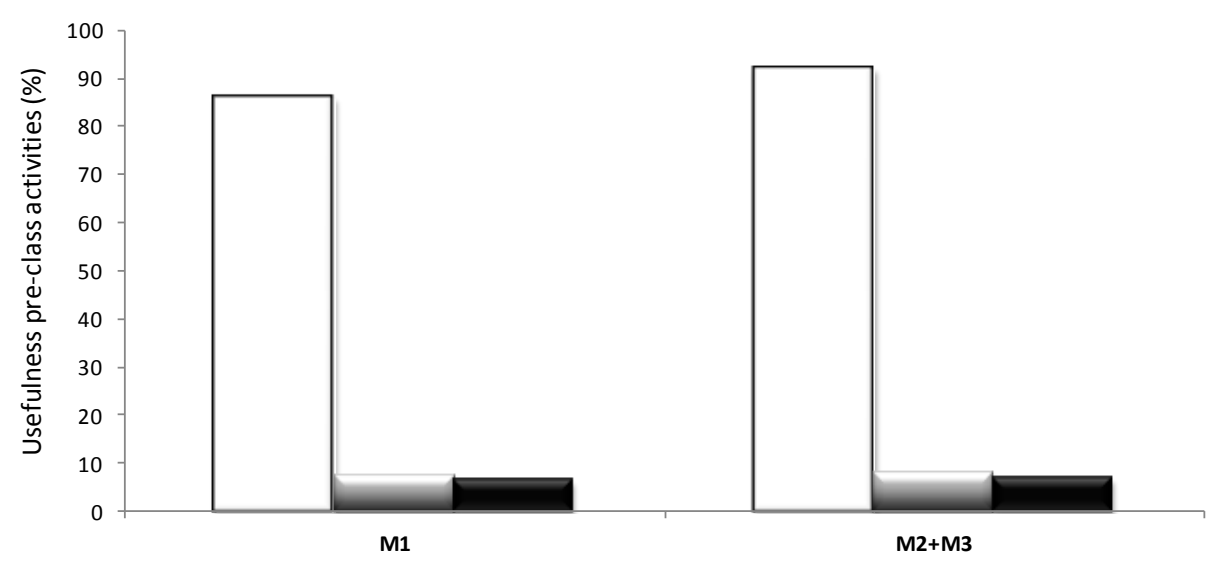

Figure. 1. Relevance of pre-class activities for students' learning process. Results were separated into Module 1 (M1) and Modules 2 and 3 (M2+M3). Categories indicate "In agreement" (white), "Neither agree nor disagree" (grey); and "Disagree" (black).

\subsection{Usefulness of technological tools for material comprehension}

The use of TICs has been shown to greatly improve the comprehension of basic and complex concepts necessary to the learning of a subject (e.g. Badia 2006; González-Coma et al. 2015). However, our students found some of the TICs more useful than others, and additionally, their usefulness was rated differently depending on the module in which they were applied (Fig. 2).

The Sicua ${ }^{+}$virtual platform was rated as being useful for learning by $88 \%$ of the students in module 1 but only $66 \%$ in modules 2 and 3. Despite asking in the focus group, we could not determine the factor that lowered the rating of SICUA+, other than that some students felt overwhelmed by the amount of content in the virtual platform. A better organization of the content may help improve the perception of the students in the following semesters.

In contrast, Socrative was found useful by $68 \%$ of the students in M1, and this went up to $77 \%$ in M2 and M3 (Fig. 2). The lower percentage in M1 was tracked to the lack of feedback on the quiz results in that module due to time constrains. The focus group after M1 suggested that more time should be spent on revising answers and explaining results. This was therefore implemented in the following modules, and likely explains the great improvement in the survey results in M2 and M3. From this, it is clear that student feedback is essential to the satisfactory development of a course and should always be solicited at several points during the semester rather than only at the end of a course. 


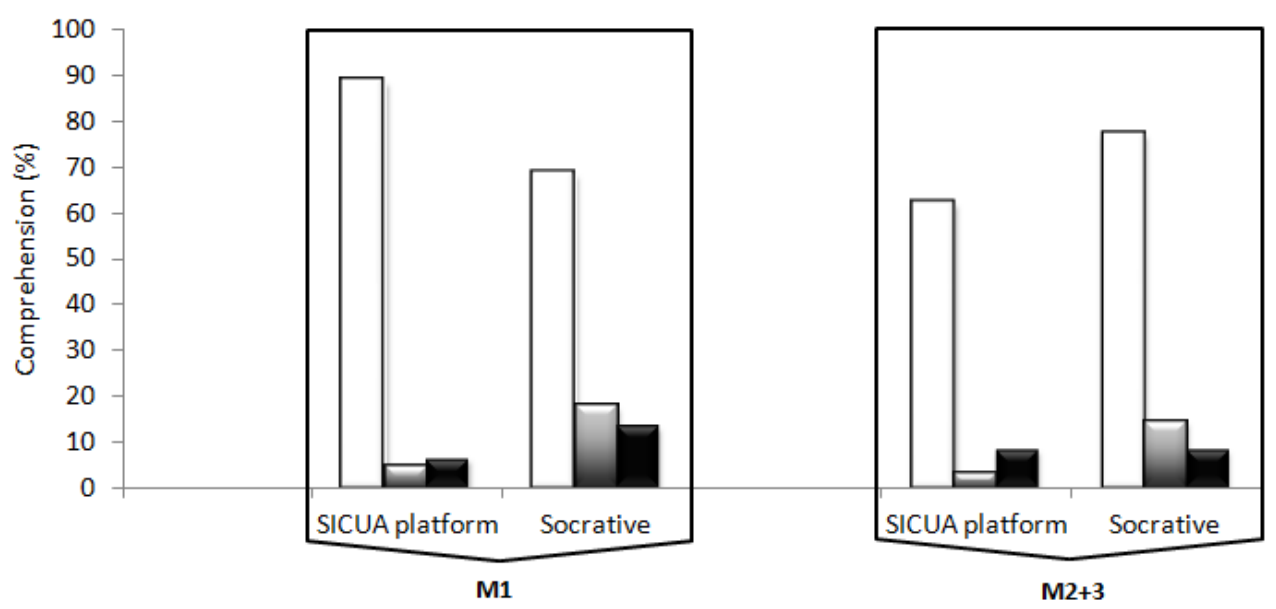

Figure. 2. Usefulness of different tools for material comprehension. Results were separated into Module 1 (M1) and Modules 2 and $3(M 2+M 3)$. Categories indicate "In agreement" (white), "Neither agree nor disagree" (grey); and "Disagree" (black).

\subsection{Importance of Socrative to Aid Interactions}

In the previous section, we discussed the importance of providing students with immediate in-class feedback and discussion of the results of their Socrative quizzes, in order for the auto-evaluation process to be effective. Here, we will focus on the significance of the online quiz app in improving interactions between students and with the teacher.

Greater interaction both among students, and between students and teacher improves the learning process through i) peer teaching between students and ii) individual teacher attention for students in big class groups.

Our results show an improvement in interactions both between the classmates and between classmates and teachers in M2 and M3 (Fig. 3).

It seems that increasing the amount of time spent in discussing answers during the class made the students feel more engaged and they increased the amount of interaction (discussion) amongst themselves in order to reach an agreement about the "right" answer to each question or problem. Providing on-the-spot feedback in class was also perceived to improve student-teacher interactions. 


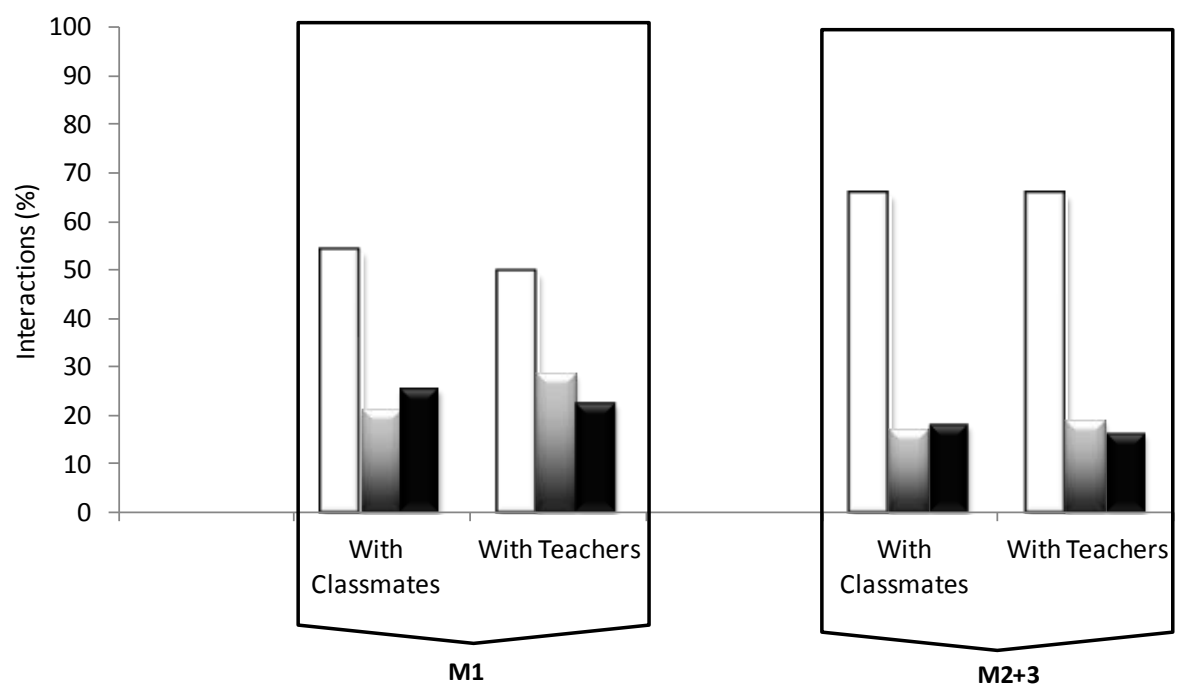

Figure. 3. How did Socrative help interactions? Results are separated into Module 1 (M1) and Modules 2 and 3 (M2+M3). Categories indicate "In agreement" (white), "Neither agree nor disagree" (grey); and "Disagree" (black).

Additionally, while all socrative quizzes were done individually in M1, during the later modules students were allowed to do some quizzes in groups which clearly had a positive effect on student-student interactions, and increased the amount of discussion and peer teaching. Students also reported that class activities helped them work in groups and that in some cases they used the same groups to study for the exams.

\section{Conclusions}

1) The technological tools used in the innovation presented here succeeded in improving student motivation and engagement with their learning process, according to online surveys and focus groups.

2) A development of transversal skills such as team work or ability to solve problems independently was also observed in the students, compared to other sections of the course that did not implement the innovations.

3) Student feedback is essential for the adequate development of the course and as such should be sought at several points during the delivery of the course, rather than only at the end of the semester. 
4) Additionally, although the data are not shown here, we found that students achieved better results overall, including a 50\% decrease in student failure rate and less than a 5\% dropout rate.

\section{References}

Badia A. (2006). Ayuda al aprendizaje con tecnología en la educación superior. Revista de Universidad y Sociedad del Conocimiento. Vol. 3 - N. ${ }^{\circ}$ 2. ISSN 1698-580X (Libro de cómo implementar las tecnologías ).

Berrett, D. (2012). How "flipping" the classroom can improve the traditional lecture. The Chronicle of Higher Education. Retrieved from http://chronicle.com/article/HowFlipping-the- Classroom/130857/

Chin C. (2007). Teachers Questioning in Science Clasrooms: Approaches that Stimulate Productive Thinking. Journal of Research in Science Teaching. Vol. 44, No. 6, PP. 815-843.

Garza, E. (2016). Aprendizaje Basado en Retos, Edu Trends. Radar de innovación educativa 2015 , 978-607-501-420-3 (1, 2016 ), 32.

González-Coma J. P., Maneiro-Catoira R., Castro P. M., Brégains J. (2015). A Software Interface as a Teaching Tool for Analysing Conformal Antenna Arrays. 1st International Conference on Higher Education Advances, HEAd'15, DOI: http://dx.doi.org/10.4995/HEAd15.2015.404

Lahuerta P., Cháfer A. (2015). eCity: Virtual City Environment for Engineering Problem Based Learning. 1st International Conference on Higher Education Advances, HEAd'15, DOI: http://dx.doi.org/10.4995/HEAd15.2015.447

Millis, B. J. (2014). Using cooperative structures to promote deep learning. Journal on Excellence in College Teaching, 25(3\&4), 139-148.

Salas, W. (2010). Formación por competencias en educación superior. Una aproximación conceptual a propósito del caso colombiano, Revista Iberoamericana de Educación, 36 (9), 25 - 09 - 05

Wallace, M. L., Walker, J. D., Braseby, A. M., \& Sweet, M. S. (2014). "Now, what happens during class?" Using team-based learning to optimize the role of expertise within the flipped classroom. Journal on Excellence in College Teaching, 25(3\&4), 253-273. 